\title{
A Study on the Individualized Information Service Mode and its Application in the Manufacturing and Supply Chain
}

\author{
Ni Yingzi ${ }^{1}$ and Qin Zheng ${ }^{1,2}$ \\ ${ }^{1}$ School of Information Management \& Engineering, Shanghai University of Finance and \\ Economics, 200433, Shanghai, China, niyingzi@foxmail.com \\ ${ }^{2}$ South University of Science and Technology of China, Shenzhen 518005, China \\ qin.zesustc.edu.cn
}

\begin{abstract}
Customer, information and functions are in the same level in the traditional computer application systems, and all customers are treated by the same interface to implement the standardized service functions. However, in general, $80 \%$ of the profits come from $20 \%$ of the key customers. These key customers should deserve better services. Therefore, the enterprises have to response quickly to their needs of individualized information service. In this paper, a detailed case of individualized information service in the field of iron and steel manufacturing supply chain is introduced, and valuable content is extracted and pushed from mass data to constitute a business environment of information sharing that creates value for the customers. The individualized information push mode for the key customer is studied and a functional frame and an operating system for the information service system based on the workflow are introduced.
\end{abstract}

Keywords: Individualized information service, Supply chain, Key customer, Enterprise system

\section{Introduction}

In the era of knowledge-based economy, it is becoming ever-increasingly difficult for organizations to create and maintain their competitive advantage [1]. Certain knowledge owned by an organization forms its competitive advantage, and the lack of certain knowledge weakens this very organization. And usually, the lack of knowledge is caused by demand of knowledge and imbalance between demand and supply [2].

Generally for a manufacturing enterprise, $80 \%$ of the profit is created by the key customers which are $20 \%$ of all customers. These strategic users should be granted outstanding service, but in most enterprise information systems, key customers and common customers are provided with the same information service, and the individualized information service demand from the key customers can hardly be satisfied rapidly. The reason is that customers, information and functions are in the same level in the traditional computer application systems, and all customers are treated by the same interface and standardized service functions [3]. 
This paper analyzes the features of collaborative operation of key customers, discusses the technical features and technical key points, and provides the functional framework of a collaborative business system for key customers and a collaborating case between an iron and steel enterprise and an automobile enterprise based on the collaborative business platform for key customers.

\section{Background of Theories}

\subsection{About Information Push Service}

Along with the advent of intelligent information era and ever-improving web data, "matching plus push" comes to replace "search", and is becoming the core of future information service. Information push technology is basically classified into two categories: automatic pulling technology and event-driven technology. In this regard, WU Jianxia ${ }^{4}$ analyzes the application of information push technology in a library system while Tong-Seng [5] carry out an analysis into push service delivery that is based upon wireless technology.

Based on previous studies, we come to notice two distinctive features: one is that one can draw advantages by combing push and pull technologies in order to achieve synergy of push and pull of information, and the other is that push technology augmented with artificial intelligence, which is signified by: Intelligent search agent technology, Automatic classification information processing technology and Intelligent information filtering technology. And particularly for the latter feature, those academic observations were applied into the study of Push technology.

\subsection{About the Individualized Push System}

The individualized information push system introduced by Zhang [6] and Qiu [7] consists of an intelligent and complicated decision making and reasoning feedback mechanism which is used to help the user fix the information so that the user can obtain the most updated information without visiting the fixed website repeatedly, and it has solved the defects in the search engine and retrieving tool by which usually excessive but not exact enough information can be found. By making the user the key focus and providing customized information push service to the user, this individualized information push system connects the user with more affinity and bridges the gap between the enterprise and the user, which is key to the improvement of user satisfaction [8].

The individualized information push system described by Chen et al. [9] basically consists of six modules: data integration, data normalization treatment, information analysis, information matching, and user utilization evaluation.

\subsection{About the Information Push Application}

According to the related references about information push, the practice of 
information push in most Chinese and foreign enterprises is supported by the push technology and realized by the information push system. Based upon observations on the performance of data service of The Johns Hopkins University of the U.S. by SHEN and Virgil [10], Davidson [11] analyzes data management programs that are currently carried out in the U.K., and concludes that the information push takes the dominant place in individualized libraries, but less so in the supply chain of the manufacturing industry.

\section{Features of Collaborative Business for Key Customers}

A strategic cooperating partnership is created by the enterprise with key customers to reduce the operation cost and improve the management efficiency, and a collaborative business platform is built for key customers with the electronic business technology. By the information exchange between strategic partners, barriers of information communication in the business flow are pushed down, the capability of rapid response is enhanced, the processing cycle of each business link is shortened, the management cost is reduced, the operating efficiency of the mutual supply chain is heightened, and the satisfaction degree of key customers is improved by the individualized and allaround customer service and business collaboration. The collaborative business of key customers is all-around and involved in many fields including research, development, distribution, manufacturing, material circulation, and service, e.g.,

1. Highly effective product research and development: the enterprise studies the technology for using, and participates in the customer's research and development workflow so that the products can be matched with the device, design and production workflow in downstream enterprises to improve the "using quality" of products.

2. Dynamic plan collaboration: the customer's plan is also the enterprise's plan, by sharing the strategic customer's production plan and production achievement and creating a material demand computing model of the supply chain between the enterprise and the customer a reasonable and exact stock quantity for varies products can be obtained, the net demand for each type can be known, and a reliable basis for material purchase can be provided to key customers.

3. Convenient information tracing: the customer can inquire about the production progress, material circulation, quality information and settlement information of the contract related in the office via electronic business. Such transparent operating mode can standardize the internal management of the enterprise.

4. High quality after-sales service: in case of any product quality problem, the customer can trace all information from project establishing, processing, claiming for compensation, correcting and completing. 


\section{Individualized Information Service Mode}

\subsection{Main Features of Individualized Information Service}

The individualized information service demand from key customers is presented on the individualized interface design, business collaboration and information push service.

1. Individualized operating interface: the computer interface design is individualized according to the business features of the key customer in consideration of the way orders are placed, operating time and interface distribution, etc. For example, Shanghai Baosteel has two key customers: Guangdong Galanz Group (the largest microwave oven manufacturer in China) and FAW (a large automobile manufacturer in China). As steel material ordered by Galanz is usually transported along the water way, Galanz may ask to select water way preferentially other than the railway on the ordering interface; but FAW usually asks to select railway transportation to Changchun Station. Furthermore, the interface distribution and menu settings are optimized, frequently used information can be searched by clicking a key once, the functional menu is arranged in a flow chart, and the correlation among all service functions can be known by the user conveniently. In all, the operating interface is simple and clear with minimal operating time and clicking times.

2. Individualized service information collaboration: a shared data collection interface is created for both cooperating parties, the product research, development and production plan and production achievement from both parties are acquired timely to organize business collaboration. For example, steel is researched and manufactured with the upgrading with car types in FAW. Once the demand for car model is fixed, a steel material certification plan with material type classified will be created in the system, the process design plan will be adjusted rapidly, and production will be spread effective to provide new steel material product for trial using. And meanwhile, shearing, punching and welding of steel in FAW can be traced by the system so that the product quality can be continuously improved before the whole car is certified.

3. Timely information push service: an individualized information space opened for each key customer all related information and functions are centralized as per the business flow, and the customized service is provided via the Internet (Web or special SLD). For example, if the globally most updated information about steel research and development is needed by Shanghai Volkswagen, information about new material and new technology released by major steel corporations and major steel magazines (e.g., Metal Abstract or Metal Engineer, etc) can be automatically searched before confirmed and pushed to the individualized information platform of Shanghai Volkswagen.

Modern communication technology such as short messaging can be used by the system to inform the related person of processing the information at the first time when a demand (opinion or query) is delivered from the customer via the collaborating business platform automatically so that the time delay in information transmission and communication can be reduced and rapid response can be realized 
effectively.

\subsection{Key Technology in Individualized Information Service}

The front operating interface must be a customized system to satisfy the individualized information service demand from the key customers, but how to design the back-end application processing system? It will not be economical and cannot be managed effectively if a background system is independently customized for each key customer. In fact, the customers' demand for information can be satisfied by the current system data resources except there are some tiny differences in interface mode, arrangement, function and content. Therefore, it is necessary to create a uniform background information processing center by which information push service is provided, all customers' demands are further concluded into workflows and forms for format conversion, bill exchange and workflow control to realize the flexible system management.

1. Format conversion: automatic conversion between individualized bills and standard bills for each enterprise can be realized in the bill format conversion center so that each partner in the supply chain can only focus on his own related data content and format during the data interface development.

2. Bill exchange: when the address code to be delivered with the business data is given from the application system, the data can be transmitted to the system at the other end by the exchange center via the function of "address registering and automatic address searching", the difference in data integration is shielded, and the system expandability is improved effectively.

3. Workflow control: format bills are described by business bills and definitions so that they can be transferred among different partners and the business information can be transferred more timely, reliably and intelligently. The relationship of information transfer is maintained by the workflow control center to follow the change of business rules and information demands among enterprises.

\section{Functional Frame of the Collaborative Service System for Key Customers}

\subsection{Core Functions of the Collaborative Service System for Key Customers}

The collaborative service system for key customers is highly different from the traditional information system. The internal information is extended to the customer and supplier via an electronic business platform to promote the informationization of the whole supply chain, realize the information integration and share among enterprises, reduce the process management cost between the upstream and downstream units, and create value for all customers. Based on the original internal business system, three core application supporting systems including an electronic business system, a supply chain decision making and supporting system and a client service knowledge base system 
Electronic business system - create a bridge between the enterprise and the customer. An electronic business platform is created for the enterprise by the electronic business technology to realize the connection from the internal system of the enterprise to the customer. Firstly, products can be ordered via the Internet conveniently. Secondly, inquiring via the Internet can be realized, the contract with customer, production progress, material circulation and transportation, quality information and settlement information of the customer's contract can be inquired by the customer in his own office. Such transparent operating mode constitutes the supervision by the clients for internal employees and standardizes the internal management. For example, if the customer finds no production is timely arranged for this contract, he can urge the arrangement via the "Hotline for Customers" so that products can be delivered on time. Thirdly, once any dispute on product quality happens and a dispute on product quality is submitted by the customer, the whole course from dispute establishing, processing, claiming for compensation and correcting can be traced.

Supply chain decision making and supporting system - support rapid responses to the customer. An order from the customer usually involves small batches and many types which must be actualized in a short time but frequently changes. In the past, such demand was usually from the least customers, and it can be treated fully in a manual mode. But now, such demand becomes frequent for the enterprise. To solve the contradiction between "individualized customer's demand" and "scaled enterprise production", it is necessary to develop an enterprise information system for supply chain management. The enterprise will actively participate in the customer's organization's production, estimate the customer's demand exactly, create a B2B information connection, and use the model technology to optimize the own organization for production. Information technology is used to create a system collaboratively operated with the customer's business, the scale advantage of industrialized production can be realized by the enterprise, the customer's contract can be completed and all customers' demands can be satisfied in quality, quantity and time. A model for estimating the customer's demand is developed to analyze the integrated optimization of supply chain between the customer and manufacturer, for example, what material and when it will be used by the customer's production line, and how to ensure the supply for production before optimizing the stock structure timely, i.e.: the own sales plan is fixed according to the customer's production plan, once the customer's plan is modified, the steel sales plan will be adjusted correspondingly. A production model will be developed and optimized, the internal ordered production and optimized organization will be studied, the contradiction between the "individualized customer's demand" and the "scaled enterprise's production" will be solved to realize the large scale customization. The production for the contract will be reasonably arranged according to the customer's demand and the own production conditions by optimized computer tools to realize the dynamic response of the delivery period.

Customer service knowledge base system - integrate the customer service information resources for knowledge sharing. To support the customer's query for ordering, the salesman has to know the product's sales history, price information, production capacity, quality assurance capacity, claim for compensation and customer's credit, etc. The information is controlled by the sales, manufacture, 
financial and other departments separately, the salesman in the past can only master the sales information and other information has to be replied by other departments in a long time and low efficiency. Information technology is used to integrate and share the information, a knowledge base is created for customer consultancy, any information can be inquired by the front sales and service men timely on line, the customer's demand for ordering can be replied at the first time, and thus rapid response and scientific decision making can be realized effectively.

\subsection{Information Correlation between the Electronic Business Platform and the Internal Management System}

The spatial and temporal distance between manufacturer and the customer is shortened by the application of the Internet and electronic business technology. The online marketing service provided by the electronic business platform for the enterprise has created an information bridge between the enterprise and the customer. The electronic business platform is closely integrated with the integrated manufacture subsystem, data warehouse subsystem, rapid response subsystem and other special management subsystems in the enterprise to answer the customer's demand and share manufacture information with the customer. For example of steel products, the main information exchange is involved with:

Sales management: customers can directly query for ordering and order on line, by the connection between the network and integrated manufacture subsystem, data warehouse subsystem and rapid response subsystem, the interaction between business and information can be realized effectively, and the management efficiencies for both parties can be improved.

Material circulation management: GPS/GPRS technology is used to position and trace the truck or ship, share the sales and material circulation information with the customer, and realize the informationized management for the transporters. The transferring speed of packet data, work instructions, coded bill information, transportation bill information and contract settlement speed are accelerated by the electronic transmission of bills based on the code bar technology of steel products.

Service management: the service system of the online marketing subsystem is functioning through the whole business flow before, during and after distribution, involved with production introduction, standard inquiry, contract trace, quality assurance inquiry, quality dispute, user's hotline, satisfaction degree investigation, and provides all-around service to the customer. In the collaborative business for key customers, the satisfaction degree of key customers is improved by the fully individualized and all-around service and business collaboration, a closer strategic partnership is created between the enterprise and the customer, and a powerful support is provided.Case of application

\subsection{Collaborative Business between Baosteel and FAW-Volkswagen}

Baosteel is one of the largest iron and steel group in China, and one of the major products is the cold rolled steel panel for automobiles. FAW-Volkswagen is a key customerof Baosteel, the automobile steel panels of Jetta, Bora and Audi, etc. are 
mainly from Baosteel, more than 6,000 tons of steel is supplied from Baosteel monthly.

In 2003, a strategic cooperation agreement was signed between Baosteel and FAW to create a collaborative business platform, to reduce the material circulation cost and improve management efficiency. The management of the steel sheet roll warehouse of FAW-Volkswagen is authorized to Baosteel. Therefore, the management of Baosteel is extended from the plant to the customer, the warehouse is created at the door to the customer, as shown in Fig. 1.

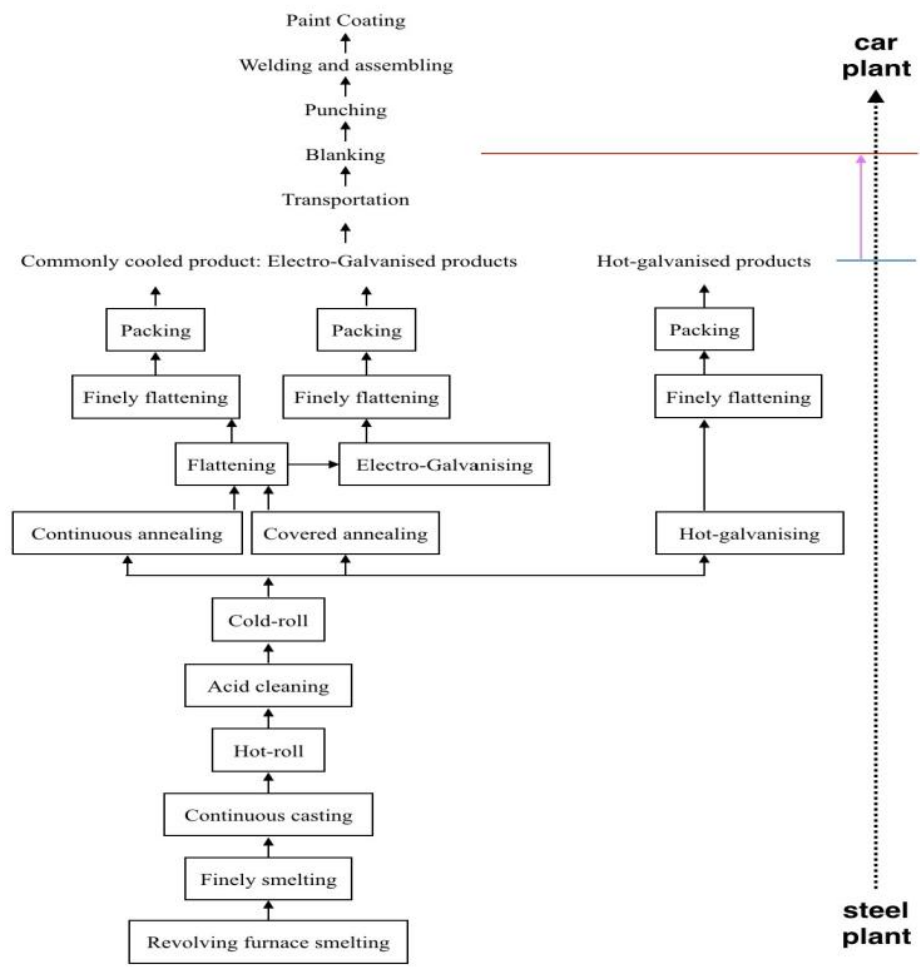

Fig. 1. Schematic drawing of business workflow between Baosteel and FAW-

Volkswagen

A steel supply chain computing model is created between Baosteel and FAWVolkswagen by the computer system, by sharing the car production plan and achievement with FAW-Volkswagen, the steel stock in the whole supply chain from Changchun to Shanghai can be dynamically balanced, the steel production plan can be adjusted timely, the contract actualization, manufacture, and finished product transportation in Baosteel can be reasonably arranged, and the demand for car production from FAW-Volkswagen can be satisfied. A "Just In Time" supply mode is realized to solve the trouble back at FAW-Volkswagen.

By the mutual effort, the steel stock in FAW-Volkswagen becomes more reasonable, the material purchase cycle is highly shortened, and the delivery accuracy 
is effectively improved. By the high efficiency supply chain management and informationized collaboration platform, the cooperation level between both parties is improved, and a promising benefit is brought to both parties. In this way, a stable and reliable strategic customer is obtained by Baosteel with value is created for the customer.

\subsection{Production Plan Collaboration between Baosteel and FAW-Volkswagen}

The core of production plan collaboration is a material demand management system for the supply chain, and the system is used to calculate the net demand (from FAWVolkswagen). The core modules are supply chain material circulation information model, production demand calculation model and purchase demand calculation model, etc. All business links including car production plan, net material demand calculation, purchase plan confirmation, steel purchase contract generation, manufacture, contract trace, material circulation, transportation and product delivery are realized on the collaborative business platform for key customers between Baosteel and FAWVolkswagen, and the effective contract data can be directly accepted by the internal business system of Baosteel.

1. The customer's stock information is integrated with the steel stock information of Baosteel production, delivery, and transportation, and a material circulation information model for the whole supply chain is created between Baosteel and FAW-Volkswagen.

2. A production demand calculation model is created according to the car production plan and fixed consumption of FAW-Volkswagen to obtain the corresponding steel demand via conversion.

3. A net demand for purchase is fixed by the purchase demand calculation model according to the safe stock days, railway transportation cycle and steel stock deducted, and finally a purchase plan is reviewed, approved and fixed.

4. The purchase plan is automatically converted into a steel ordering contract and transmitted into the internal business system of Baosteel via electronic processing.

5. The manufacture information and railway transportation achievement of Baosteel can be timely fed back to the collaborative business platform, and the stock structure of the whole supply chain can be dynamically traced by both parties.

\section{Conclusion}

The individuality of any customer is not specially treated in the traditional information system, the positions of key customers and ordinary customers are same and same functions are used in the system. Therefore the individualized customer's demand is restricted by the common system functions. Differentiated information service will become more and more popular with the improvement of customer's level. A customized and individualized information service system is created for FAW-Volkswagen by Baosteel based on the supply chain collaboration theory for 
business collaboration and information share. From the case of production and material circulation collaboration between Baosteel and FAW-Volkswagen, we find: the material demand calculation for the whole supply chain is more accurate than the independent MRP calculation in the enterprise because of the expansion of calculation range and the improvement of information transparency, and the customer's raw material stock becomes more reasonable. And meanwhile by the mutual all-around information collaboration, paperwork is greatly reduced, the production plan flexibility and response level are improved, and the operation is simplified effectively. Therefore, a larger value space is created for both parties by the individualized information service for key customers.

\section{References}

1. Zack, M.H.: Developing a knowledge strategy. California Management Review 41(3), 124125 (1999)

2. Fan, Z., Sun, Y.: Enterprise Knowledge Management Strategy based on SWOT Analysis. Nankai Business Review 5(4), 4-6 (2002)

3. Zhang, X., et al.: The Study on Information Service for Strategy Customer in B-B eBusiness Model. In Proceedings of International Conference on Service Systems and Service Management, Beijing China, pp. 769-772 (2004)

4. Wu, J.: Principle of Information Push Technology and its Application in the Library. SciTech Information Development \& Economy 14(3), 19-21 (2004)

5. Tong-Seng J.: Push selling-Multicast messages to wireless devices based on the publish / subscribe model. Electronic Commerce Research and Applications 1, 235-246 (2002)

6. Zhang, Y.: Individualized Knowledge Push System based on Search Engine. Information and Technology 6, 60-61 (2004)

7. Qiu, Y., Pan, X., Qiu, J., Gu, X.: WEB-Based Knowledge Management and design of its software system structure. Manufacturing Automation 24(14), 15-18 (2002)

8. Li, Y.: Study on Quality Assessment System of Client-focused Digital Information Push Service. Liaoning Normal University 2011

9. Wei, C., et al.: On Measuring Cloud-Based Push Services. International Journal of Web Services Research 13(1), 53-68 (2016)

10. Shen, Y., Virgil, E. Varvel, Jr.: Developing Data Management Services at the Johns Hopkins University. The Journal of Academic Librarianship 39, 552-557 (2013)

11. Davidson, Y., Jones, S., Molloy, L., Kejser, U.B.: Emerging Good Practice in Managing Research Data and Research Information within U.K. Universities. Procedia Computer Science 33, 215-222 (2014) 